environmentalists have had unparalleled opportunity for field work in the past decade. This has involved the photography of the area from manned and unmanned spacecraft, ground-level geophysical surveys (which on one occasion discovered glaciers far to the south of where they were expected) and the drawing up of ecological guidelines for the engineers. There must be no tree-felling on slopes of more than 15 degrees and no insecticides - construction gangs plagued by the ubiquitous Siberian mosquitoes must use protective netting or swatters.

In spite of all this care, a recent report from the Chita Hydrometeorological Observatory suggests that the development of the BAM zone is running into environmental problems. In the north Transbaikal area, it appears, there is very little wind; the air masses remain static for a considerable time and industrial emissions become concentrated. Long before the BAM railway itself is officially opened, the pollution in the Chara valley is already, say the Chita scientists, some 50-100 per cent greater than that in the European part of the USSR - the centre, at present, of Soviet industry.

\title{
CORRESPONDENCE
}

\section{Biko's doctors}

SIR, - The Faculty of Medicine of the University of the Witwatersrand has strongly attacked the decision of the South African Medical and Dental Council that there was no evidence of improper or disgraceful conduct on the part of the doctors who treated $\mathrm{Mr}$ Steve Biko before his death in detention. The Faculty Board has resolved unanimously to dissociate itself publicly from the council's decision, taken at a closed meeting on 17 June 1980.

At a meeting held on Friday, 27 June, the Board of the Witwatersrand University Medical Faculty unanimously adopted a resolution on the "Biko doctors". The resolution reads: "The Faculty of Medicine of the University of the Witwatersrand, Johannesburg, has considered the decision of the South African Medical and Dental Council, taken at a closed meeting on 17 June 1980 , that there was no evidence of improper or disgraceful conduct on the part of the doctors who treated Mr Steve Biko before his death, and that there was thus no need for a disciplinary hearing.

"Bearing in mind the revelations under cross-examination at the inquest, and the fact that the magistrate presiding at Mr Biko's inquest had considered that the matter of the Biko doctors should be referred to the South African Medical and Dental Council, the Faculty expresses its deep concern and disquiet at the finding that there was no evidence of improper or disgraceful conduct and that the matter should be dropped. The faculty feels that there was prima facie evidence of improper or disgraceful conduct, which should have been subjected to the careful scrutiny of a Medical Council Disciplinary Committee hearing.

"The Faculty is of the opinion,

furthermore, that this decision of the Medical Council may seriously affect the good standing of the South African medical profession both at home and abroad and, therefore, publicly dissociates itself from this decision.

Further, the Faculty endorses and supports the Guidelines for Medical Doctors concerning Detainees and Prisoners, adopted by the 29th World Medical Assembly of the World Medical Association in Tokyo in October, 1975, and known as the "Declaration of Tokyo". This states, inter alia, that a doctor must have complete clinical independence in deciding upon the care of a person for whom he or she is medically responsible (Article 5), and that a doctor shall in all circumstances be bound to alleviate the distress of his fellow men, and no motive - whether personal collective or political - shall prevail against this higher purpose (Article 8).

"The Executive of the Board of the Faculty of Medicine is requested to ensure that the views of the Board are communicated widely to the public and to the medical community, both in South Africa and abroad,"

In accepting this resolution, the Faculty stressed that "We are not saying that the doctors are guilty. We are saying that there is sufficient evidence for a Disciplinary
Committee enquiry to be instituted and that a decision should be taken about the behaviour of the doctors on the basis of a full, fair, impartial and thorough Disciplinary Committee hearing. The South African

Medical and Dental Council is supposed to be the watch-dog of the ethics of our profession and they have been zealous - and some would suggest over-zealous - in the severity of the punishment that they have meted out, not only for major infringements but for what many would regard as minor infringements of the ethics of medical practice. Yet, in the presen case, it is difficult to accept that the Medical and Dental Council has applied its collective mind to the problem of the Biko doctors in a purely objective and dispassionate way."

In moving the resolution, Professor Clive Rosendorff, Head of the Department of Physiology at the Medical School, made this statement:

"This is all a source of great embarrassment and distress to many doctors in South Africa who are proud of the high ethical standing of their profession, both within this country and abroad. I believe that we have a responsibility to indicate to the world that we disapprove of the decision of the Medical Council to drop the matter. We should like it to be known that we dissociate ourselves, as an institution and as a body of concerned citizens and doctors, from their decision. We do this because we feel that it is morally indefensible for a matter as important and serious as this to be dropped before it has reached the Disciplinary

Committee stage. We do this because we feel that the ethical standards of our profession have been compromised; because as doctors we have a humane concern for our patients and their welfare; because we are worried about the possible effects of the decision of the Medical Council on the future treatment of prisoners and detainees by the authorities; and because we are worried about the repercussions of the Medical Council's decision abroad. Already there are signs of a campaign to cut ties with doctors from South Africa, both at international congress level and in the recognition of our degrees abroad.

"Countries with which we have most dealing and reciprocity agreements, Great Britain, Australia, New Zealand, the Netherlands, Belgium, the United States of America, Canada, have always been happy to accept the bona fides of the S.A. Medical and Dental Council. However, there are already indications that rethinking on this point has started. The British Medical Association Ethics Committee is to examine the Biko doctors decision of the S.A. Medical and Dental Council. In Geneva, the World Health Assembly has called on member countries to review their medical ties with South African doctors.'

My Faculty believes that it is vitally important that we distance ourselves from the decision of the Council. As a group of concerned doctors and Medical School teachers, we are worried that the South African Medical and Dental Council might, by its decision, have called in question its own credibility as an objective and unbiased guardian of the high standards of the medical profession in South Africa. Yours faithfully,

Dean, Medical School, Phillip V. Tobias

University of Witwatersrand,

Johannesburg, S.A.

\section{Russian continues}

Sir, - May I, as Head of the Department of Russian and Soviet Studies at the University of Lancaster, be allowed to comment briefly on

Vera Rich's piece in the last issue of Nature (3 July). Her remarks concerning the diminishing provision for the study of Russian in Britain, in contrast to the proposed expansion in Finland, are entirely justified. Her statement, however, suggesting there has been an

"overnight decision to close down the Russian Department of the University of Lancaster' is incorrect and seriously misleading.

As part of a broader policy document which purported to be a strategy for the 1980 s, a small Vice-Chancellorial committee at Lancaster recently recommended the gradual phasing-out of five small academic departments, including Russian. The document was subjected to widespread and vociferous criticism throughout the University and was finally withdrawn at a meeting of the University Senate on 11 June.

The department, therefore, still exists and will continue to exist - with an increased undergraduate enrolment in 1980-81.

Moreover, in addition to its full degree programme of Russian history, politics, language and literary studies, and in the context of your article, it plans to mount a new elementary Russian language course which will be available for scientists who wish to acquire a reading knowledge of Russian and hence gain access to a major "medium of scientific communication'" Yours faithfully,

University of Lancaster, UK AI.AN WOOD

\section{Dioxin disclaimer}

SiR, - I wonder if you would be kind enough to allow me to comment on Alastair Hay's article in Nature (6 March) which indirectly implies that I had some part in the nonpublication of the two investigations of Coalite workers.

Firstly I was never involved in the treatment of Coalite cases. Secondly, not only did I never suggest suppression of the data, but 1 repeatedly urged its publication unsuccessfully.

It should be mentioned that the second and more far-reaching study to which Hay has referred was suggested to Coalite by the HSE since the first study was considered inadequate. I have never been shown the results of this second study by the company but obtained them by unofficial means. Yours faithfully,

Princess Margaret Hospital K.D. CROW Swindon, UK 